\title{
Studies on sensory characteristics of Sandesh by incorporating with mango pulp (Mangifera indica L.) cv. ALPHONSO
}

\author{
V. N. PATIL, R. M. KADAM, SONALI JADHAV AND A. A. HANMANTE
}

\begin{abstract}
Sandesh is the one of the most popular traditional milk products in Indian subcontinent. Pattern of milk production in India indicates that about 6 per cent of the milk produced is coagulated to produce Chhana. Out of this, about 80 per cent is used for manufacture of Sandesh. The efforts are made in the present investigation to add the value ofSandesh by incorporating the mango pulp @ 7.5 per cent, 15 per cent, 22.5 per cent and 30 per cent of weight of Chhana. The different sesory characteristics were determined. It is concluded, the cow milk Chhana best for Sandesh preparation.Sensory characteristics i.e. colour and appearance, flavour, body and texture of Sandesh was done using hedonic rating scale then it is concluded that score increasing with addition of mango pulp upto 22.5 per cent level of mango pulp $\left(\mathrm{T}_{3}\right)$ then decline significantly with increase in the level of mango pulp. From the results of present investigation it may be concluded that mango pulp could be successfully utilized for preparation of Sandesh. Addition of mango pulp in cow milk Sandesh improved sensory quality and acceptability of the product. For incorporation of Sandesh the optimum level of mango pulp found to be 22.5 per cent on the basis of weight of Chhana.
\end{abstract}

KEY WORDS : Cow milk, Chhana, Sensory evaluation, Mango pulp, Statistical analysis

HOW TO CITE THIS PAPER : Patil, V.N., Kadam, R.M., Jadhav, Sonali and Hanmante, A.A. (2017). Studies on sensory characteristics of sandesh by incorporating with mango pulp (Mangifera indica L.) cv. ALPHONSO. Res. J. Animal Hus. \& Dairy Sci., 8(2) : 79-84 : DOI: 10.15740/HAS/RJAHDS/8.2/79-84.

Address for correspondence :

V. N. Patil, Department of Animal Husbandry and Dairy Science, Dr. Balasheb Savant Konkan Krishi Vidyapeeth, Dapoli, RATNAGIRI (M.S.) INDIA

Email : vishalpt139@gmail.com

Associated Authors':

R.M. Kadam, Sonali Jadhav and A.A. Hanmante, Department of Animal Husbandry and Dairy Science, Dr. Balasheb Savant Konkan Krishi Vidyapeeth, Dapoli, RATNAGIRI (M.S.) INDIA 